\title{
EL METABOLISMO EN MARX: APUNTES DESDE LA ONTOLOGÍA DEL TRABAJO
}

\section{METABOLISM IN MARX: NOTES FROM THE ONTOLOGY OF LABOUR}

\author{
Moisés García PaLACios* \\ UNED
}

\begin{abstract}
Resumen: En la obra madura de Marx hay una definición del trabajo articulada en torno a la metáfora del metabolismo entre seres humanos y naturaleza. En el presente artículo pretendemos mostrar que dicha definición pertenece al ámbito de la ontología, pues hay tanto un interés metódico en presentar el trabajo en su forma esencial y abstracta - antes de cualquier subsunción en un sistema económico concreto- como una tarea desveladora.
\end{abstract}

Palabras ClaVE: Marx, ontología, trabajo, mediación, cuerpo, naturaleza, ser social, producción.

АвSTRACT: In Marx's mature work, there is a definition of labour that is articulated around the metaphor of the metabolism between humans and nature. In the present article we intend to show that this definition belongs to the scope of ontology because there is a methodical interest in presenting labour both in its essential and abstract forms - before any subsumption in an economic system — and as an reveiling task.

Keywords: Marx, ontology, labour, mediation, body, nature, social being, production.

*Doctorando. C/ Velayos 18, 6º. 28035 Madrid. moigpalacios@gmail.com 


\section{Introducción}

Se puede considerar que Marx estableció en El capital una definición ontológica del trabajo - una definición esencial y general del proceso de trabajo-con el objetivo de establecer el fundamento desde el cual desarrollar su exposición pormenorizada del proceso de producción capitalista. Sería un error creer que Marx hipostasió una determinada forma concreta e histórica de trabajo (por ejemplo, el trabajo asalariado) convirtiéndola en una forma universal de la actividad laboral. Por el contrario, con el objetivo de establecer la crítica al modo como se crea el capital Marx definió dos procesos concomitantes e inseparables en el modo de producción capitalista: el proceso de trabajo y el proceso de valorización. Estos dos procesos conjuntos conforman una "unidad inmediata", sin embargo, sólo mediante el trabajo real se consume la capacidad viva del trabajador, que acaba convirtiéndose en plusvalor y, por lo tanto, en capital.

Nuestro interés se centra en el proceso de trabajo en cuanto que condición natural de la capacidad creativa humana, para ello mostraremos el significado filosófico y ontológico que Marx dio al término metabolismo [Stoffwechsel]. Con el objetivo de exponer la dimensión crítica que dicho término tiene en la obra de Marx vamos a hacer un breve recorrido por ella, desde los Manuscritos del 44, los Grundrisse, los Manuscritos del 61-63 o El capital. Acto seguido, en el tercer apartado, detallaremos cuál es la génesis y la formación de la noción Stoffwechsel. En el último apartado, desde una perspectiva filosófica, analizaremos el metabolismo como una categoría crítica del ámbito de la ontología del trabajo en su labor desveladora.

\section{La noción Stoffwechsel en la obra de Marx}

Si bien el término Stoffwechsel sólo está presente en la obra de Marx desde los Grundrisse (1857-1858) hasta las Notas sobre Adolph Wagner (1880), es posible encontrar las primeras intuiciones al respecto en los Manuscritos parisinos (1844):

La naturaleza es el cuerpo inorgánico [unorganische Leib] del hombre; la naturaleza, en cuanto ella misma, no es cuerpo humano. Que el hombre vive de la naturaleza [Mensch lebt von der Natur] quiere decir que la naturaleza es su cuerpo, con el cual ha de mantenerse en proceso continuo [beständigem Prozeß] para no morir. Que la vida física y espiritual del hombre está ligada 
[zusammenhängt] con la naturaleza no tiene otro sentido que el de que la naturaleza está ligada [zusammenhängt] consigo misma, pues el hombre es una parte de la naturaleza [Mensch ist ein Teil der Natur] $(2013,141)$.

Interesa señalar de esta cita que sólo mediante el trabajo el ser humano puede mantener con la naturaleza un "proceso continuo para no morir» [beständigem Pro$z e ß]$. El trabajo, entendido como actividad genérica y universal [Gattungswesen] de carácter vital y natural, establece una conexión y un vínculo [zusammenhängt] entre la comunidad humana y la naturaleza, una conexión interdependiente entre dos partes naturales que se copertenencen. La actividad laboral se comprende en este nivel como actividad inmanente a la propia naturaleza, con otras palabras, el ser humano no sólo transforma y se autotransforma con dicha actividad, sino que, en cierto sentido, la naturaleza, a través del ser humano, se transforma a sí misma. Esto nos permite comprender el trabajo como un proceso [Prozeß] de carácter natural que ha de establecerse ininterrumpidamente para mantener con vida el cuerpo orgánico humano.

Esta intuición referente a la unidad y a la relación que se establece entre ser humano y naturaleza a través del trabajo comienza a convertirse en un concepto más formado y completo a partir de los Grundrisse de 1857-1858. En este texto se pueden señalar dos significados de la noción Stoffwechsel que serán mantenidos en la obra madura de Karl Marx. Por un lado, el término es traducido por "procesos fisicoquímicos naturales» para referirse con ello a los procesos de descomposición y desintegración concerniente a los entes que han sido producidos en tanto que valores de uso y son consumidos socialmente -al modo como una entidad orgánica social gigantesca lo haría-, o simplemente devorados por el devenir incesante de la realidad:

Estas sustancias suyas son ahora, por lo tanto, perecederas, ni siquiera tendrían valor de cambio alguno si no tuvieran valor de uso; como valores de uso pierden su valor, se disuelven por simples procesos fisicoquimicos naturales [Stoffwechsel] si no se las utiliza realmente, o si se las utiliza realmente desaparecen de manera total [cursiva mía] $(1982,212)$. 
En otro contexto, Marx se refiere al Stoffwechsel en tanto que transformación química o mecánica propia de las sustancias que componen el producto por medio del trabajo o al proceso por el que se combinan las diferentes sustancias sin alterar el valor:

El trabajo es una actividad orientada a un fin, y por ende, con arreglo al aspecto material, está presupuesto que en el proceso de producción el instrumento de trabajo sea utilizado realmente como un medio para un fin, y que el material en bruto, como producto, haya recibido un mayor valor de uso, mediante el intercambio quimico de sustancias [chemischen Stoffwechsel] o la transformación mecánica, que el que antes poseía [cursiva mía] [...]

Si esos elementos, a partir de la forma del movimiento, del proceso al final de éste se combinan nuevamente en una forma objetiva, inmóvil, en el producto, es éste igualmente un mero intercambio de sustancias [Stoffwechsel] con respecto al valor, al que no altera [cursiva mía] (ib., 251-253).

Cabe señalar que Marx en los Grundrisse comienza a dar otro sentido al término. En efecto, hay un uso metafórico cuando se refiere tanto a la circulación de mercancías en el intercambio simple o en la circulación de capital (Vol. II, 1972, 151 y 187), como al propio proceso de producción del capital, al cual identifica con el organismo humano:

Por cuanto el proceso de producción del capital es a la vez un proceso tecnológico [...] de determinados valores de uso [...] de todos estos procesos de producción aparece como el más fundamental aquel a través del cual el cuerpo reproduce el necesario metabolismo [Stoffwechsel], vale decir, crea los medios de subsistencia en el sentido fisiológico [...] [cursiva mía] (ib.,154)

La simultaneidad del proceso del capital en diferentes fases del proceso [...] este cambio de forma y de sustancia [Stoffwechsel] [se opera] como en el cuerpo orgánico [cursiva mía] (ib., 180). 
Observamos, entonces, que en los Grundrisse el término Stoffwechsel es aplicado a los diferentes modos de intercambio material o de sustancias en un sentido metafórico, estableciendo símiles con el ámbito orgánico. No obstante, el significado que irá tornándose hegemónico será aquel que defina el modo ontológico de producir y trabajar en su forma general, siendo el metabolismo social del capital la forma alienada de ese proceso originario ${ }^{1}$ :

Las condiciones originarias de la producción [...] originariamente no pueden ser ellas mismas producidas, no pueden ser resultados de la producción. Lo que necesita explicación, o es resultado de un proceso histórico, no es la unidad del hombre viviente y actuante, [por un lado] con las condiciones inorgánicas, naturales, de su metabolismo [Stoffwechsel] [cursiva mía] con la naturaleza, [por el otro,] y, por lo tanto, su apropiación de la naturaleza, sino la separación entre estas condiciones inorgánicas de la existencia humana y esta existencia activa, una separación que por primera vez es puesta plenamente en la relación entre trabajo asalariado y capital (vol. I, 1982, 449).

Quizá Marx no estimaba oportuno desarrollar la unidad viviente y actuante entre seres humanos y naturaleza por motivos prácticos, en aquel momento interesaba en primer lugar exponer cómo el capital se adueña de esa unidad al modo como un parásito o un virus penetran en el organismo vivo. Sin embargo, lo que en 1857 no necesitaba explicación dada su obviedad hoy ha quedado fetichizado ${ }^{2}$ después de siglo y medio de desarrollo capitalista. En la era de la subsunción real (cf. Marx, 1971) del trabajo en el capital el fundamento vital y

1 István Mészáros en Más allá del capital (2001) se refiere al metabolismo social del capital como aquel tipo de metabolismo social entre seres humanos y naturaleza caracterizado por una división estructural y jerárquica del trabajo en dependencia al capital, lo que genera una sumisión y subsunción de los aspectos vitales y esenciales del trabajo a los requisitos totalitarios del capital. Este sistema, articulado en la tríada capital, trabajo y Estado, se ha vuelto incontrolable y destructivo en virtud de sus propias determinaciones internas.

2 «El fetichismo consiste en un mecanismo cognitivo por el que se oculta en una relación (el cuarto predicamento de Aristóteles) el momento fundamental (es decir, el fundamento oculto) de lo que aparece (superficialmente). Esto se logra al interpretar como absoluto el término fundado relativo de la relación [...] En la relación dialéctica de "(A) trabajo vivo" con "(B) valor" puede igualmente negarse el trabajo vivo del trabajador como fuente creadora del valor (su creador, y esencia del capital), y con ello el valor aparece como originándose a sí mismo, 
originario del trabajo no aparece como un momento determinante sino como un aspecto relativo y determinado a la valorización del capital, produciéndose un ocultamiento del fundamento en detrimento del término relativo, en otras palabras, el trabajo, fuente creadora del valor, aparece en la fetichización propia del sistema económico capitalista como término relativo y dependiente del valor. El fondo ontológico del trabajo, en cuanto que unidad del ser humano y la naturaleza, queda fetichizado en una relación alienada en la que el término natural y vivo queda subordinado a la mera relación comercial y mercantil en la que el trabajo depende del capital, es decir, del dinero en tanto que salario, que no es más que una forma o momento de la circulación y valorización del capital.

Dicho esto, en los Manuscritos 61-63 Marx hará uso del término para referirse al proceso de trabajo en sentido general -ontológico- de una manera muy parecida a como más tarde aparecerá en El capital:

Como quiera que el trabajo real es la apropiación de la naturaleza para la satisfacción de las necesidades humanas, actividad a través de la cual el metabolismo [metabolism, Stoffwechsel] [cursiva mía] entre el hombre y la naturaleza es mediada [...]

[...] es la condición universal de la interacción metabólica entre la naturaleza y el hombre, y como tal condición natural de la vida humana, es independiente de, igualmente común a, todas las formas sociales particulares de la vida humana [trad.: M. García Palacios] (Marx, 2010a, 40 y 63).

Asimismo, la noción Stoffwechsel es empleada para referirse al proceso de consumo y descomposición propio del devenir de la realidad: «Una máquina que no sirve en el proceso de trabajo es inútil, madera y hierro muerto. Aparte de esto es víctima del consumo de las fuerzas elementales, del metabolismo universal [de la naturaleza] [trad.: M. García Palacios]. Compárese esta cita con esta otra de El capital: «Una máquina que no presta servicios en el proceso de trabajo es inútil. Cae, además, bajo la fuerza destructora del metabolismo natural [natürlichen Stoffwechsels]. El hierro se oxida, la madera se pudre» (2010b, 1. I, 222).

como capital, y en este caso el capital pretende crear valor desde sí, de la nada (de trabajo).» (Dussel, 2014, 114-115). 
Ahora bien, la intuición de juventud que se ha ido desarrollando a lo largo de su obra queda perfilada y conceptualmente completa en el Capítulo V del Libro I de El capital, lugar en el que explica el proceso de trabajo con estas palabras:

El trabajo es, en primer lugar, un proceso entre el hombre y la naturaleza, un proceso en que el hombre media [vermittelt], regula y controla su metabolismo [Stoffwechsel] con la naturaleza. El hombre se enfrenta a la materia natural misma como un poder natural. Pone en movimiento las fuerzas naturales que pertenecen a su corporeidad, brazos y piernas, cabeza y manos, a fin de apoderarse de los materiales de la naturaleza bajo una forma útil para su propia vida. $\mathrm{Al}$ operar por medio de ese movimiento sobre la naturaleza exterior a él y transformarla, transforma a la vez su propia naturaleza. Desarrolla las potencias que dormitaban en ella y sujeta a su señorío el juego de fuerzas de la misma [cursiva mía] (2010b, 1. I, 215-216).

Al final de este capítulo vuelve a definir el proceso de trabajo en general antes de ser subsumido en ningún sistema económico concreto. Ésta es la definición ontológica del trabajo: el trabajo en cuanto que categoría simple aún no determinada por condiciones históricas concretas:

El proceso de trabajo, tal y como lo hemos representado en sus elementos simples y abstractos, es una actividad orientada a un fin, el de la producción de valores de uso, apropiación de lo natural para las necesidades humanas, condición general del metabolismo [Stoffwechsel] entre el hombre y la naturaleza, eterna condición natural de la vida humana y por tanto independiente de toda forma de esa vida, y común, por el contrario, a todas sus formas de sociedad [cursiva mía] $(i b ., 223)^{3}$.

\footnotetext{
3 Hemos preferido usar la traducción de Pedro Scaron para estos específicos fragmentos, esta elección está motivada por la traducción que hace él del término «Stoffwechsel» en cuanto que metabolismo. Creemos que Pedro Scaron acierta al traducirlo por «metabolismo», pues está teniendo en consideración tanto una problemática y discusión propia de la época de Marx como un sentido metafórico más apropiado para la definición general y abstracta del proceso de trabajo. La palabra alemana Stoffwechsel literalmente significa «intercambio de materia», de esta manera es interpretada por algunos traductores (e. g. Manuel Sacristán, Wenceslao Roces
} 
Encontramos, de nuevo, este sentido en el Capítulo XLVIII del Libro III La fórmula trinitaria, refiriéndose al trabajo como abstracción:

La actividad productiva del hombre en general, por medio de la cual opera el metabolismo [Stoffwechsel] con la naturaleza, despojado no sólo de toda forma social natural, independiente de la sociedad sustraído de toda sociedad y como manifestación y afirmación de vida común al hombre que no tiene todavía nada de social y al hombre social en cualquiera de sus formas [cursiva mía] (2000, 1. III, t. III, 267).

O refiriéndose a la hipotética sociedad de productores libre asociados:

En este terreno, la libertad sólo puede consistir en que el hombre socializado, los productores asociados, regulen racionalmente este metabolismo [Stoffwechsel] con la naturaleza, lo pongan bajo su control común, en vez de estar dominados por él como por un poder ciego; llevarlo a cabo con el menor gasto de fuerza y bajo las condiciones más dignas y adecuadas a su naturaleza humana [cursiva mía] (ib., 273).

Este breve recorrido sobre el uso que hace Marx del término Stoffwechsel en su obra madura concluye con lo que afirma en las Notas sobre Adolph Wagner de 1880: "También usé la palabra en el proceso "natural" de producción en el metabolismo [Stoffwechsel] entre hombre y naturaleza» $(1987,377)$.

y Vicente Romano), sin embargo, no creemos que la traducción literal sea la correcta. Podría parecer que entender el trabajo como un «intercambio de materia» entre ser humano y naturaleza lo dota de un sentido materialista cercano al pensamiento de Marx. No obstante, creemos que ese sentido literal no expresa lo mismo que el concepto metabolismo: en primer lugar, el concepto de «metabolismo» tuvo una génesis precisa que Marx conocía; en segundo lugar, entender el trabajo en su dimensión ontológica como un mero «intercambio de materia» nos lleva a una concepción materialista vulgar, la cual no reconoce la potencia transformadora y autotransformadora de la actividad vital productiva. 
Como hemos visto la noción de metabolismo aparece de manera frecuente en la obra madura de Marx, aun cuando la idea de mediación entre ser humano y naturaleza a través del trabajo era ya una intuición en los Manuscritos del 44, acabó conceptualizándose en torno a la metáfora del metabolismo. Antes de exponer qué sentido filosófico y ontológico tiene este término procede presentar cómo fue posible que Marx lo usara para definir el proceso de trabajo.

\section{Génesis y formación de la noción Stoffwechsel en relación al metabolismo}

El término Stoffwechsel empezó a utilizarse en el campo de la medicina a principios del siglo XIX ${ }^{4}$, no obstante, fue a mediados de esa misma centuria cuando comenzó a hacerse frecuente su uso para referirse a lo que hoy es común llamar «metabolismo», es decir, a "la red integrada de reacciones bioquímicas que mantienen la vida de un organismo» (Lawrence, 2003), a través de un continuo flujo de materia y energía, por el cual, mediante un complejísimo conjunto de transformaciones, se obtienen moléculas sencillas para componer otras moléculas más complejas 5 .

Con anterioridad a los fisiólogos alemanes de la década de los cuarenta del siglo XIX, el proceso de transformación de los alimentos ya había sido estudiado por los médicos hipocráticos, al que denominaron «cocción», en analogía a lo que sucede con la manipulación y elaboración de los alimentos en la cocina. El médico ítalo Sanctorius (1561-1636) manejará una proto-noción de metabolismo en relación a su perspiratio insensibilis (transpiración insensible) (ib., 158). Este término, fruto de la comprobación empírica de la pérdida de materia a través de la piel y los pulmones, suponía que el organismo está continuamente sufriendo cambios, y que la suma total de estos cambios constituye la base físicoquímica de la vida.

Ya en los siglos XVII y XVIII, junto con el desarrollo de la incipiente ciencia química, empezó a considerarse que la nutrición estaba relacionada con las

\footnotetext{
4 Según F.C. Bing el primer caso que encuentra del término «metabolismo» es una mención de la palabra en un artículo de 1815 (1971, 168).

5 Aportamos la definición que ofreció en 1913 el profesor L. J. Henderson y que es del gusto de F.C. Bing: «'Metabolismo' es el término aplicado al flujo de materia y energía y sus transformaciones intermedias dentro del organismo [trad.: M. García Palacios]» (ib., 178).
} 
fermentaciones o las reacciones ácido-alcalinas, procesos que se incluyeron dentro de la llamada economía animal, en similitud a la economía doméstica. Sin embargo, Lavoisier estableció un cambio de perspectiva sobre el funcionamiento de ese complejo conjunto de transformaciones. Para él la respiración había de considerarse como un proceso de combustión lenta que necesitaba carbono e hidrógeno, y emitía calor y trabajo.

No obstante, el desarrollo de la química orgánica dio como resultado una comprensión más completa y formada del conjunto de procesos químicos que se dan en los seres vivos. En el ambiente científico de los años cuarenta de la Alemania del siglo XIX se acuñó el término «Stoffwechsel» para designar a dicho proceso. Aunque Justus von Liebig en su Química animal de 1842 no usa el término «Stoffwechsel» sino "Metamorphose» (ib.: 172), cabe destacar el uso de una noción más amplia para referirse a los intercambios que se producen en torno al contexto de la degradación tisular. Esto implica que el proceso metabólico comienza a extenderse como concepto clave de la bioquímica, pero aplicado no sólo a nivel celular sino también a los organismos enteros. Sin embargo, como nos dice J. B. Foster (2004, 246-249), Liebig será criticado por Julius Robert Mayer en 1845 en su artículo «El movimiento de los organismos y su relación con el metabolismo» porque Liebig mezcla el concepto de metabolismo con la noción de fuerza vital -que se entendía como una herencia de la tradición del «materialismo vital»-, y cuyo objetivo principal era evitar los enfoques mecanicistas de la bioquímica. De este modo, Mayer entendía que la noción de fuerza vital era innecesaria y que el metabolismo [Stoffwechsel] debía explicarse en términos exhaustivamente energéticos (conservación e intercambio).

Es sabido que Marx conocía a través de Engels la obra de Mayer, y que en 1864 estudió la obra del fisiólogo alemán Theodor Schwann (ib.: 248). Éste había introducido en 1839 la noción de «metabolismo celular» y fue una referencia tanto para Mayer como para Liebig. Precisamente Schwann -en un tratado sobre la teoría de la célula- fue el primero en utilizar el adjetivo metabolische. Adjetivo que los traductores franceses tomaron y extendieron a la literatura científica, traduciendo a partir de ese momento el término "Stoffwechsel» por "le metabolisme».

Así pues, desde 1840 hasta nuestros días el metabolismo se ha constituido en una categoría de primer orden en la comprensión que la teoría de sistemas hace de la interacción entre los organismos y su medio, desde la célula hasta los ecosistemas. Sin duda, y compartiendo la opinión de Foster, el metabolismo: 
"Comprende el complejo proceso bioquímico del intercambio metabólico, a través del cual un organismo (o una célula dada) se sirve de los materiales y la energía que encuentra en su medio y, por medio de una serie de reacciones metabólicas, los convierte en los elementos constructivos de su crecimiento" (ídem).

Una vez contextualizado el origen y el desarrollo del término en cuestión podemos detallar a grandes rasgos su sentido filosófico y metafórico en torno al trabajo.

\section{Sentido filosófico y ontológico del metabolismo}

Marx empleó la metáfora del metabolismo para referirse al proceso de trabajo. Asimismo, esta metáfora contiene la definición ontológica del trabajo, es decir, en el análisis del proceso de trabajo que hace Marx se muestra la actividad laboral en su forma general -aún no subsumida en ningún sistema económico-, de tal suerte que el trabajo aparece en su forma esencial, simple y abstracta ${ }^{6}$. Como el propio Marx afirma en El capital: «Por tanto, el proceso de trabajo debe considerarse, de momento, independiente de toda forma social determinada" (2000, 1. I, t. I, 241). La exposición del proceso de trabajo es el punto de partida para el análisis del proceso de valorización, sin embargo, aquí nos interesa como proceso de producción en general, en el cual se objetiva la vida subjetiva de los y las trabajadoras. Es importante conocer y mantener esta distinción entre proceso de trabajo y proceso de valorización, debido a que en el capitalismo se da como un proceso «inmediato» y concomitante (Marx, 1971, 21). De este modo, la crítica al capitalismo es una crítica categorial al trabajo, en tanto que en este sistema económico concreto el proceso de trabajo y el proceso de valorización aparecen unidos como si del mismo proceso se tratase: la plusvalía -el capital-se crea únicamente en aquel momento del proceso de trabajo que no es retribuido ${ }^{7}$. El trabajo en el capitalismo es un momento del capital, es decir, un momento

\footnotetext{
6 Seguimos el punto de vista de Jaques Bidet: «Aquí, "abstracto” no se opone a "concreto” en el sentido empírico, de cosa existente por oposición a las ideas, sino que califica, dentro de la construcción teórica, el momento más general, por oposición a las elaboraciones conceptuales que se siguen de él y que definen fenómenos determinados» $(2012,15)$.

7 Moishe Postone en Tiempo, trabajo y dominación social (2006), aporta una reinterpretación de la teoría crítica de Marx evitando hipostasiar la categoría de trabajo, es decir, en la crítica al capital el trabajo no puede aparecer como un hecho natural y transhistórico, sino como un momento del capital en su proceso de valorización.
} 
fundamental del proceso de valorización. La reducción del trabajo a momento del proceso de valorización del capital (el trabajo en cuanto capital [Arbeit als Moment des Kapitals] $)^{8}$ conlleva que el trabajo aparezca como si fuera relativo al propio capital, y no como su verdadero fundamento. Por consiguiente, la crítica categorial al trabajo es sólo el preludio a una aproximación ontológica al mismo9. La pregunta: «¿qué es el trabajo?» tiene entonces hoy plena validez, pues el trabajo ha quedado fetichizado, ensombrecido y oculto bajo el poder omnímodo del capital. Esta es la tarea de una ontología del trabajo: el intento de mostrar el poder productor (poiético $)^{10}$ de esta actividad vital-práctica-humana en la época de la subsunción real.

Analicemos entonces el trabajo, en primer lugar, hay que añadir que este proceso o metabolismo es una mediación [Vermittlung] entre los seres humanos y la naturaleza. Sin la actividad laboral la naturaleza quedaría extraña y ajena a la propia humanidad, pues la naturaleza como tal sólo adquiere sentido para nosotros cuando ha quedado mediatizada por nuestra actividad. Mediante el trabajo la naturaleza se humaniza y el ser humano se naturaliza. Ahora bien, la cuestión del trabajo como mediación requiere que se aclare cuál es el carácter de la relación que se establece entre ser humano y naturaleza. Esto es así porque parece que sólo tiene sentido hablar de mediación cuando ésta actúa como una función que establece una relación entre dos elementos en principio heterogéneos. De esta manera resulta contradictorio concebir, por un lado, al trabajo como una mediación entre ser humano y naturaleza, y, por el otro, al ser humano como parte de la naturaleza [pars naturae]. En este sentido nos resulta extraña la afirmación de Alfred Schmidt en El concepto de naturaleza en Marx: "[...] frente a la unidad del hombre con la naturaleza se afirma su carácter irreconciliable, es decir, en

\footnotetext{
8 La subsunción del trabajo al capital -en cuanto momento de éste- aparece in nuce en la obra de Marx desde los Manuscritos del 44 (Marx, 2013, 162).

9 Aquí se tiene en consideración lo que Bruno Gullì expone en Labor of fire: the ontology of labor between economy and culture (2005): si bien la categoría de trabajo es un constructo de la economía política, el trabajo en sí, considerado ontológicamente, esto es, como trabajo vivo creador, no puede ser enteramente velado ni subsumido por el capital, pues forma parte de la vida misma.

10 Si bien en la Antigüedad había una distinción clara entre theoría, praxis y poíesis en virtud de la inmanencia o trascendencia del fin de la actividad, en la Modernidad no puede haber más que una reflexión que aúne la praxis y la poíesis. Esta es la tesis revolucionaria de Marx según Balibar $(2002,47)$ : no se puede pensar la producción de nuevos entes sin las condiciones ético-políticas en las que es posible dicha producción.
} 
última instancia, la necesidad del trabajo» $(2011,26)^{11}$. Es el ser humano un cuerpo físico, finito, de carne, sensible y sufriente que establece relaciones con el medio que le rodea y con otros congéneres. Entender la naturaleza como algo externo al ser humano es olvidar que el ser humano es naturaleza, que el cuerpo y la conciencia son desarrollos evolutivos de la naturaleza misma. Ahora bien, que el ser humano sea parte de la naturaleza y que se relacione con otros seres (humanos o no) como partes de la naturaleza no implica que dicha relación sea de carácter inmediato. Si bien el ser humano en sus orígenes mantenía relaciones de carácter inmediato con el medio y con el resto de seres vivos, merced al desarrollo de la técnica y la organización social que la acompaña, se va generando una creciente mediación entre el ser humano (ser social y comunitario) y la naturaleza. En un principio los objetos de su necesidad estaban a la mano en el mundo, estaban presentes inmediatamente, pero el desarrollo histórico y social humano fue cambiando esa relación inmediata por otra mediata. La producción implica un proceso de mediación entre seres humanos y naturaleza, en virtud del cual la naturaleza es transformada mediante la aparición de nuevos objetos proyectados por la conciencia, con la cualidad de satisfacer la necesidad humana a nivel material (trabajo) o espiritual (arte).

Por otra parte, si acudimos a la etimología del término «metabolismo» ésta nos conduce a la teoría del cambio en Aristóteles, en concreto, a la que está relacionada con la producción: la generación o génesis ${ }^{12}$. Aunque el significado del término metabolé puede concebirse como cambio, tráfico o trueque, en nuestro estudio cabe interpretarlo como transformación. Este sentido pertenece al ámbito del cambio ontológico, esto es, -tal y como muestra Aristóteles en la Metafísica- cuando el cambio no sólo afecta a los accidentes sino también a la sustancia (transmutatio, mutatio, permutatio) se considera que es un cambio de tipo entitativo o sustancial.

11 No compartimos la visión de A. Schmidt según la cual el ser humano ha de estar siempre en lucha contra la naturaleza: «[...] Marx [...] se sirve del término Stoffwechsel [intercambio orgánico $],[\ldots]$ cuando examina la mutable, pero en el fondo insuprimible lucha del hombre con la naturaleza» $(2011,84)$. Esta visión, según nuestro entender, permanece aún en el interior de las metafísicas de la dominación, pues la creencia en la eterna lucha y separación de la naturaleza es un intento de dominación. Hecho en realidad ilusorio, como mostraron Adorno y Horkheimer en Dialéctica de la ilustración (2005), pues al tratar de dominar la naturaleza el dominio recae, finalmente, sobre el propio ser humano.

12 Nos vamos a centrar fundamentalmente en el Libro VII, cap. VII de la Metafísica. 
Para el Estagirita todo lo que se genera se genera bajo la acción de algo, proviene de algo y llega a ser algo (2000, 1032a 13-16, 286-287). Estas generaciones pueden darse por naturaleza o por la acción técnica humana. El proceso productivo supone, entonces, un tipo de cambio entendido como devenir, esto es, como algo que «está por llegar a ser» o "está siendo», que está en proceso. Estar en proceso es un modo de estar in fieri, es decir, es el modo de ser de algo que se está haciendo. Esa es la determinación esencial de la poíesis, a saber, la generación o génesis de un ente artificial mediante la técnica humana ${ }^{13}$.

En la metabolé, por tanto, hay una generación y corrupción de sustancias que permite concebir la metáfora de Marx más allá de la biología y la química molecular, y transferirla a la producción [poiesis] como ya hiciera Aristóteles. La poíesis no es un simple movimiento kinético sino que implica un devenir y una transformación de una materia prima mediante la actividad productiva. Para Marx el proceso de trabajo, el trabajo en cuanto trabajo — la producción mismaes el metabolismo entre seres humanos y naturaleza, lo que implica un proceso regulado por la conciencia a través del cual los seres humanos componen y descomponen múltiples sustancias generando y destruyendo nuevas entidades. El ser humano es un ser natural y viviente, un ser finito y limitado que, para mantener su corporalidad y conciencia, debe establecer una constante e ininterrumpida relación con la naturaleza. Su estructura orgánica requiere de los componentes inorgánicos esenciales para continuar viviendo y desarrollando todas sus potencialidades. Es la necesidad ${ }^{14}$ la que convierte al ser humano en un ser activo, vitalmente activo, que ha de encontrar o producir aquellos objetos esenciales que requiere tanto para su subsistencia como para la creación de un mundo cultural nuevo. El punto de partida es por lo tanto un ser natural activo que subsiste a través de su metabolismo con la naturaleza mediante su actividad vital.

13 Cabe recordar que en la producción [poiesis] no se generan entidades desde la nada [ex nibilo nibil fit], no hay creación sino generación desde una materia prima.

14 La noción de «necesidad» puede resultar ambigua y estar cargada ideológicamente, de modo que exponemos la definición que Enrique Dussel nos da en 16 tesis de economía políti$c a$ : "Llamamos necesidad a la captación emotivo-cognitiva que siente la subjetividad viviente (en el ámbito del sistema límbico cerebral, principalmente) de la falta de (es una negatividad física primera) un satisfactor posible que pueda reponer la materia y la energía consumida que no pueden dejar de estar presentes en el proceso vital. La necesidad se funda entonces en el hecho mismo físico, real, empírico de la corporalidad del sujeto humano como viviente [...]» $(2014,19)$. 
La metáfora biológica empleada por Marx nos conduce al centro ontológico del trabajo. Como afirma György Lukács en Ontología del ser social: el trabajo (2004), en el metabolismo con la naturaleza se muestra «la auténtica actividad del hombre», en tanto que surge un nuevo nivel del ser sobre la base del ser inorgánico y orgánico, creando una realidad más compleja $(2004,79)$. Lukács concibe el metabolismo como la forma originaria del trabajo, esto es, "como una forma que siempre se mantiene por encima de la variación de las formaciones sociales» (ib., 96). La noción de metabolismo nos muestra la inherente relación que existe entre el estrato inorgánico, orgánico y social. Cada estrato gana en complejidad con respecto al anterior, subsumiendo a los estratos menos complejos en nuevos estratos más ricos en complejidad. Lo orgánico se constituye a través de lo inorgánico en un nivel cualitativo superior, como lo social se constituye desde lo orgánico y lo inorgánico, subsumiendo sus niveles de complejidad. Teniendo en cuenta estas relaciones de complejidad y subsunción se puede afirmar que la universalidad propia del ser social expresa la esencia genérica [Gattungswesen] humana, convirtiendo a la naturaleza entera en su cuerpo inorgánico [unorganischen Körper]. Sin embargo, la naturaleza no es sólo ese ámbito físico, material e inorgánico desde el cual el ser humano se nutre, sino que también es su cuerpo vivo y experimentado, es su mundo de la vida. Como ya vimos en la cita de los Manuscritos del 44 (2013, 141), la naturaleza, por una parte, es el cuerpo inorgánico en tanto que es «un medio de subsistencia inmediato», a saber, «la materia, el objeto y el instrumento de su actividad vital». Por otra parte, el ser humano "vive de la naturaleza», esto es, "la naturaleza es su cuerpo» [Die Natur ist sein Leib]. Como más tarde diferenciará la fenomenología ${ }^{15}$, el Körper es considerado como la representación de índole científica que se hace del organismo, es decir, el cuerpo considerado como objeto. Por el contrario, el Leib es el cuerpo en tanto que sujeto que puede ser experimentado y vivenciado. De este modo, un cuerpo puede tener peso, medida y ocupar un espacio determinado. Pero un cuerpo también crea la espacialidad y la temporalidad del mundo que habita, además está situado en un mundo que le es familiar y al que condiciona y es condicionado por él. Un cuerpo [Körper] puede pesar, pero también un cuerpo [Leib] puede sentirse pesado. El cuerpo del cual se ocupa la ciencia [Körper] puede ser

15 Cf. E. Husserl Ideas II (2005) y los artículos de Javier San Martín «Apuntes para una fenomenología del cuerpo» (2002) y Jesús Adrián «Heidegger y la Hermenéutica del cuerpo» (2011), en relación a la distinción que se establece entre Körper y Leib a partir del pensamiento fenomenológico. 
traducido como "cuerpo material» y el cuerpo de la fenomenología [Leib] puede ser traducido por «cuerpo vivo»" ${ }^{16}$.

Esta distinción nos hace tener en consideración una dimensión del metabolismo que no queda reducida al intercambio orgánico o inorgánico. Si, como afirma Marx, la naturaleza es su cuerpo [Leib], y ha de mantenerse en continuo proceso con ella, es debido a que la vida no queda reducida a su aspecto puramente biológico y mecánico, sino que tanto la "vida física» como la «vida espiritual» están «ligadas» a la naturaleza, y esto es así en la medida que el ser humano es parte de la naturaleza. El metabolismo implica tanto al ser inorgánico, al ser orgánico, como al ser social, por lo tanto, los tres estratos del ser quedan interrelacionados en el proceso general de trabajo que desarrolla el ser humano. Desde los niveles menos complejos del ser a los más complejos, el trabajo, como actividad específicamente humana de producción, crea y constituye un mundo, un mundo social y cultural que supone una novedad con respecto al mundo natural. El ser humano establece, por consiguiente, determinadas relaciones sociales e históricas en su metabolismo con la naturaleza a través del trabajo, convirtiendo el «medio vital corporal» en un «medio social» (Fischbach, 2014, 59). El trabajo, en su forma aún no subsumida ni alienada, no es sólo el medio de interacción con la naturaleza, sino la posibilidad misma del desarrollo social humano.

\section{Conclusiones}

Tras exponer tanto la noción de metabolismo en la obra madura de Marx como su preciso origen a comienzos del S. XIX, hemos querido proponer un análisis ontológico del trabajo en torno a la definición que el propio Marx estableció en El capital, finalmente obtenemos las siguientes conclusiones:

16 «Esa distinción también se halla de alguna manera presente en el diccionario etimológico de los hermanos Grimm, donde Leib se asocia al latín "vita", "persona” y Körper se remonta al sentido médico de "corpus" [...] Y si bien esta distinción resulta bastante intuitiva, la cosa se complica a la hora de encontrar una traducción clara y eficaz para los términos Leib y Körper y las expresiones que se enmarcan en sus respectivos campos semánticos, en particular leiblich y Leiblichkeit, por una parte, körperlich y Körperlichkeit, por otra. A la luz de la diferencia entre la noción científica y fenomenológica de cuerpo, podemos traducir Leib como "cuerpo vivo" y Körper como "cuerpo material". Otras traducciones optan por traducir Leib por "soma” y conservar el término "cuerpo" para Körper.» (Adrián, 2011, notas 10 y 11) 
La definición ontológica del trabajo tiene un interés metódico, es decir, para una mejor explicación de la realidad concreta (el trabajo en el capitalismo) se parte de una definición abstracta y general del trabajo: el metabolismo.

Esta definición, en sí misma, no es una realidad concreta, pero nos permite mostrar las determinaciones esenciales que constituyen al trabajo. Aquí nos hemos ocupado de la mediación, la transformación o el cuerpo, pero también podriamos haber expuesto la temporalidad, la objetividad o el ente producido, etc.

Marx partió de lo abstracto para explicar lo concreto, en eso consistía el método dialéctico. Para explicar el capital y su proceso de valorización se comienza con categorías simples, una de ellas es el trabajo en cuanto que trabajo, la esencia del trabajo.

A parte de la cuestión metódica, el análisis ontológico del trabajo nos permite desvelar la esencia de una actividad oscurecida por la ideología productivista. En la era de la subsunción real el poder poiético humano no aparece como evidente, sino como consecuencia de un conjunto de fuerzas que ahora le dominan como extrañas. Más allá del campo económico hay un ámbito irreductible al valor de cambio: el ámbito de la propia vida, el metabolismo con la naturaleza. 


\section{Bibliografía}

Adrián Escudero, Jesús (2011). Heidegger y la hermenéutica del cuerpo. Observaciones filosóficas, 11, 20-45.

Aristóteles (2000). Metafísica. Intr., trad. y notas: Tomás Calvo Martínez. Madrid: Gredos.

Balibar, Étienne (2000). La filosofía de Marx. Trad.: Horacio Pons. Buenos Aires: Nueva Visión.

Bidet, JaCQues (2012). Los filósofos no han hecho más que interpretar de diversos modos El capital. Sobre por qué hay que transformarlo y cómo hacerlo. En: Fischbach, Franck. Marx: releer El capital. Trad.: Francisco López Martín. Tres Cantos: Akal.

Bing, Frankinn C. (1971). The History of the Word 'Metabolism'. Journal of the History of Medicine and Allied Sciences. Vol. 26 (2), 158-180.

Dussel, EnRIQue (2014). 16 tesis de economía politica: interpretación filosófica. México D.F.: Siglo XXI.

Fisbach, Franck (2014). La production des hommes: Marx avec Spinoza. París: Librairie Philosophique J. Vrin.

Foster, John Bellamy (2004). La ecología de Marx: materialismo y naturaleza. Trad.: Carlos Martín y Carmen González. S.l.: Ediciones de Intervención Cultural/ El Viejo Topo.

Gullì, Bruno (2005). Labor of fire: the ontology of labor between Economy and Culture. Philadelphia: Temple University.

Horkheimer, Max; Adorno, Theodor W. (2005). Dialéctica de la Ilustración: fragmentos filosóficos. $7^{\mathrm{a}}$ ed. Intr. y trad.: Juan José Sánchez. Madrid: Trotta.

Husserl, Edmund (2005). Ideas relativas a una fenomenologia pura y una filosofía fenomenológica: libro segundo investigaciones fenomenológicas sobre la constitución. $2^{\text {a }}$ ed. Trad: Antonio Zirión. México: UNAM; Instituto de Investigaciones Filosóficas.

Lawrence, Eleanor (Ed.) (2003). Diccionario Akal de términos biológicos. Trad.: Rocío Codes Valcarce y Francisco J. Espino Nuño. Tres Cantos: Akal. 
LukÁcs, György (2004). Ontología del ser social: el trabajo. Antonino Infranca y Miguel Vedda (ed.). Buenos Aires: Herramienta.

Marx, Karl (1971). Libro I Capitulo VI inédito; Resultados del proceso inmediato de producción. Presentación: José Arico; trad. Y notas: Pedro Scaron. México D.F.: Siglo XXI.

- (1982). Elementos fundamentales para la critica de la economía política: borrador 1857-1858. 3 volúmenes. 2a ed. Ed.: José Aricó, Miguel Murmis y Pedro Scaron. Trad.: Pedro Scaron. México D.F.: Siglo XXI. [Grundrisse der Kritik der politische Ökonomie. MEW, Band 26, Berlin: Dietz Verlag Berlin, 1983.]

- (1987). Randglossen zu Adolph Wagners „Lehrbuch der politischen Ökonomie“. En: MEW, Band 19, Berlín: Dietz Verlag Berlin.

- (2000). El capital: critica de la economía politica. 3 libros. 2a ed. Trad.: Vicente Romano García. Madrid: Akal. [Das Kapital: Kritik der politischen Ökonomie. Erster Band, Buch I: Der Producktionsprozeß des Kapitals. MEW, Band 23, Berlín: Dietz Verlag Berlin, 1968.]

- (2010a). Economic works 1861-63. En: Marx, Karl; Engels, Friedrich. Collected Works: Marx 1861-63. Vol. 30. London: Lawrence \& Wishart, Electric Book.

- (2010b). El capital: crítica de la economía politica. Ed., trad. y notas Pedro Scaron. Tres Cantos.: Siglo XXI. [Das Kapital: Kritik der politischen Ökonomie. Erster Band, Buch I: Der Producktionsprozeß des Kapitals. MEW, Band 23, Berlín: Dietz Verlag Berlin, 1968.]

- (2013) Manuscritos de economia y filosofía. $3^{\mathrm{a}}$ ed. Trad.: Francisco Rubio Llorente. Madrid: Alianza. [Ökonomisch-philosophische Manuskripte aus dem Jahre 1844. MEW, Band 40, Berlín: Dietz Verlag Berlin, 1968.]

Mészarós, István (2001). Más allá del capital: hacia una teoría de la transición. II tomos. Vicepresidencia del Estado Plurinacional de Bolivia presidencia de la Asamblea Legislativa Plurinacional (ed.) Trad.: Editorial Vadell. La Paz: Pasado y presente xxi.

Postone, Moishe (2006). Tiempo, trabajo y dominación social: una reinterpretación de la teoría critica de Marx. Trad.: María Serrano. Introd.: Jorge 
García López. Revisión de la trad. y notas de Alberto Riesco Sanz y Jorge García López. Madrid: Marcial Pons.

San Martín, Javier (2002). Apuntes para una fenomenología del cuerpo. En: RIVERA ROSALES, Jacinto y LÓPEZ SÁENZ, Ma del Carmen. El cuerpo. Perspectivas filosóficas. Madrid: UNED, 133-164.

Schmidt, Alfred (2011). El concepto de naturaleza en Marx. Trad.: Julia M. T. Ferrari de Prieto y Eduardo Prieto. Madrid: Siglo XXI.

Recibido: 25/04/2017

Aceptado: 25/07/2017

Este trabajo se encuentra bajo una licencia de Creative Commons Reconocimiento-NoComercial-SinObraDerivada 4.0

\section{cc) (i) $(9)$ \\ EY NO ND}

